\title{
Sensing polymer inhomogeneity in coated metals during the early stages of coating degradation
}

\author{
Raquel G. Duarte ${ }^{a, b}$, Sergio González ${ }^{a}$, Antonio S. Castela ${ }^{b, c}$, Mário G.S. Ferreira $^{\mathrm{b}, \mathrm{d}}$, \\ Ricardo M. Souto ${ }^{a, e}$ \\ aDepartment of Physical Chemistry, University of La Laguna, E-38200 La Laguna, \\ Tenerife, Canary Islands, Spain \\ bInstituto Superior Técnico, ICEMS, Av. Rovisco Pais, 1049-001 Lisboa, Portugal \\ 'Escola Superior de Tecnologia do Barreiro, 2830-144 Barreiro, Portugal \\ ${ }^{d}$ Department of Ceramics and Glass Engineering, University of Aveiro, 3810-193 \\ Aveiro, Portugal \\ eInstituto de Materiales y Nanotecnologías, University of La Laguna, E-38200 La \\ Laguna, Tenerife, Canary Islands, Spain
}

\begin{abstract}
Negative-feedback scanning electrochemical microscopy (SECM) is successfully applied to visualize spatially-resolved differences in the topography of coated metal samples upon exposure to aqueous electrolyte solutions of different composition. This method allows the investigation of the uptake of reactants from the electrolyte phase through the polymeric matrix to the metal/polymer interface to be performed even at early exposures. Yet, the method must be carefully checked to discard transport processes from the organic matrix into the solution phase, such as those related to lixiviation. In this later case, the topography of the polymer layer may evolve with time accordingly, not longer exclusively responding to the uptake by the polymer matrix of components from the electrolyte phase. Furthermore, lixiviated species may also react with the SECM tip, eventually leading to the continuous modification of the active surface area of the electrode during the measurements. In this work, the effect of lixiviation from a nickel foil coated with plasticized PVC (PVC Plastisol) on its topographic characterization by SECM was investigated.
\end{abstract}

Keywords: scanning electrochemical microscopy; topography; water uptake; lixiviation; nickel; PVC. 


\section{Introduction}

Surface modification of metallic materials with polymer coatings constitutes an efficient protection procedure against corrosion as they introduce a physical barrier layer that separate the metal from the corrosive environment [1-4]. But these organic layers never provide an absolute separation between the underlying substrate and the electrolyte. In fact, the permeation of water and oxygen through the polymer matrix in defect-free coated metals immediately after exposure to aqueous electrolytes is well documented [5], whereas the development of ionic pathways through the polymer is regarded to occur prior to the transport to the metal-polymer interface of other aggressive species such as the chloride ions. That is, the organic film should have already become defective before the onset of corrosion processes at the buried metal substrate. But these ideas have been greatly shaken by recent reports that a specific effect of chloride ions towards swelling of the coating and even early blister initiation in a variety of metal-polymer systems could be observed by SECM operating in the feedback mode [6-10]. In contrast, blistering could not be observed in chloride-free solutions (namely sulphate, nitrate or borate solutions have been explored so far). The direct consequence of those observations is that chloride must enhance degradation of the coating at a very early stage, certainly at significantly shorter times that coating failure could be observed by either conventional electrochemical techniques or visual observation [11,12].

The lack of confirmation of the reported effects from the use of other techniques, as well as the concern raised by the addition of redox mediators for SECM imaging, have imposed a certain caution as for the general acceptance of those observations. Conventional operation of the SECM in the feedback mode requires the measurement of a faradaic current at the sensing probe (i.e., the SECM tip) $[13,14]$, and topographic changes in an insulating surface such as the defect-free coated metal originate from local hindrance in the diffusion-limited transport of the redox mediator as the tip is moved in close proximity to the surface. Yet, the absence of swelling effects in chloride-free electrolytes of similar ionic strength [11], as well as the recent report that the same effect has been imaged by SECM without the addition of an external redox mediator by using the naturally dissolved oxygen in the electrolyte [15], were strong evidences supporting the reported features.

On the other hand, the possible occurrence of lixiviation from the polymer matrix and its effect on the topographic images obtained by SECM operated in the negative feedback mode has not been considered so far. In fact, in the above reported studies we considered no lixiviation processes to occur, or either to happen in such a minor extent that their effect on the measured data could be neglected. But during the course 
of investigations of water uptake and solution ions mobility in plasticized PVC $[16,17]$, the occurrence of lixiviation was detected, and its extent was found to greatly depend on the composition and the concentration of the electrolyte solution. To gain further confirmation on the existence of solution composition effects on lixiviation, and its possible influence on the measurement of water uptake and ion transport by SECM, experiments were conducted on a pure nickel foil coated by plasticized PVC.

\section{2.- Experimental}

The metallic substrate was pure nickel foil (0.15 mm of thickness, $99 \%$ purity) supplied by Goodfellow (Cambridge, United Kingdom). The polymer film was plasticized PVC (PVC plastisol) fabricated by Akzo Nobel Nippon Paint (The Netherlands), applied to $160 \mu \mathrm{m}$ thickness. The coated foils were cut to the desired size with a guillotine from the top coat side downwards, and measured $10 \mathrm{~mm} \times 10$ $\mathrm{mm}$. These coupons were placed horizontally in a flat-cell configuration at the bottom of the SECM cell. The 3-electrode configuration, with the SECM tip as working electrode, a Pt-wire as counter, and an $\mathrm{Ag} / \mathrm{AgCl} /$ saturated $\mathrm{KCl}$ reference electrode, was employed. The tips for the SECM studies were glass insulated, disk-shaped Pt microelectrodes (10 $\mu \mathrm{m}$ disk diameter).

Testing was performed during its immersion in electrolyte solutions at the spontaneously-developed open circuit potential. The electrolytes considered were 0.5 $\mathrm{M}$ and $0.05 \mathrm{M} \mathrm{NaCl}, \mathrm{NaF}$ and $\mathrm{CsCl}$ aqueous solutions. They were made from analytical-grade reactants and twice-distilled water. $0.5 \mathrm{mM}$ ferrocene-methanol was added to the electrolyte solutions to act as electrochemical mediator at the tip. To enable the oxidation of the ferrocene-methanol the tip was kept at a constant potential of $+0.5 \mathrm{~V}$ vs. an $\mathrm{Ag} / \mathrm{AgCl} /$ saturated $\mathrm{KCl}$ reference electrode. Measurements were performed at ambient temperature in the naturally aerated solutions. All the experimental operations were performed with the substrate being unbiased, thus allowing the measurements to be carried out on the metal-coating system without any electrochemical perturbation.

Experiments were carried out by using a Sensolytics Scanning Electrochemical Microscope (Sensolytics, Bochum, Germany), controlled with a personal computer. All measurements were carried out in a three-electrode cell, located inside a Faraday cage. The micromanipulator stand of the SECM instrument was used to hold the microelectrode in place. Scans were conducted both vertically (approach curves) and parallel to the sample surface (maps). The measurements were performed with the microelectrode at a height of $15 \mu \mathrm{m}$ over the specimen surface. 


\section{3.- Results and discussion}

When the cell and all peripherals were mounted in position, and the imposed experimental parameters had been set, the appropriate electrolyte was inserted into the cell and the microelectrode tip scanned over the surface. The establishment of the operating tip distance over the sample was performed by recording the corresponding approach curve for the oxidation of ferrocene-methanol in the electrolyte. To prevent the tip touching the surface, the movement of the microelectrode was stopped when the current measured decreased to $75 \%$ of the steady-state value in the bulk of the electrolyte. Under such conditions, the electrode was located in close proximity to the sample. Subsequently, the tip was withdrawn to $15 \mu \mathrm{m}$ from the sample surface, and the positioning motors were employed to move the tip parallel to the surface until reaching the holiday. All measurements were done by moving the tip at that fixed distance over the coated sample. SECM maps displaying the topography of the coated substrate could thus be obtained after different immersion times in the test electrolyte. A selection of the maps obtained in $0.5 \mathrm{M}$ solutions of $\mathrm{NaF}, \mathrm{NaCl}$ and $\mathrm{CsCl}$ for exposures up to 24 hours are given in Figure 1. It must be noticed that they have been plotted with the $Z$ (faradaic current) axis inverted, that is, smaller values are placed higher in the figure. The purpose was to directly display the recorded topography of the samples because smaller faradaic currents measured at the tip correspond to more hindered diffusion of the redox mediator to the sample, which happens for those portions of the substrate that protrude in the electrolyte phase and are at smaller distances from the scanning tip.

Though all the surfaces are topographically heterogeneous upon immersion of the coated samples in the three test solutions, they extent of roughening and their time evolution greatly vary with the nature of the electrolytes. Indeed, a different trend could be established in each case. In the case of $0.5 \mathrm{M} \mathrm{NaCl}$, surface roughening is observed to progressively develop with the elapse of time for the 24 hours duration of the experiment. Though the surface is somewhat flat during the first hour of immersion, a certain degree of coating swelling seems to occur already after 6 hours, and it is more observable at the end of the experiment. This result somewhat resemble those observations of early swelling of other polymer resins applied on steel induced by chloride ions, which has been named before as the specific effect of chloride towards early blistering of coated metals [6-10]. The situation is quite the opposite when the $\mathrm{CsCl}$ solution is considered instead, because the roughening diminishes with the elapse of time, being greater for shorter exposures. Indeed, major roughening is observed even after 6 hours immersion, and the flatter surface is found in this environment for the longest time. Yet, it is interesting to notice that for $0.5 \mathrm{M} \mathrm{CsCl}$ 
solution and the 24 hours exposure, the topography is not flat, but shows the rather typical rounded features commonly observed for other coatings in chloride-containing solution. Thus, though a chloride-induced effect can be invoked for the samples immersed in both chloride-containing solutions, it seems that the nature of the cation is even more pronounced at least for nickel coated with PVC plastisol. More striking is the difference in topography of the samples when NaF solution is considered instead. Very rough surfaces are observed at all times, because the topography does not change much from that already determined after 1 hour exposure. Additionally, the protrusions occur as thin peaks and no rounded features are observed this time.

From the above reported results, fluoride ions might be regarded to be more effective ions to promote surface heterogeneity in coated metals than chloride anions or the cations, though they are more strongly solvated due to their smaller size. This apparent inconsistency was further investigated using $0.05 \mathrm{M}$ concentrations of the test electrolytes, whereas the remaining experimental conditions were maintained equal in relation to the previous experiment. Figure 2 gives the SECM maps measured in the three solutions for the same exposure times as in Figure 1 for the sake of comparison. When the $0.05 \mathrm{M} \mathrm{NaF}$ solution is considered, again the greatest roughening of the surface is found for this electrolyte. Yet it is important to notice, but observing the scales used in the $Y$ axis, that roughening is even more intense in the more dilute electrolyte, and develops further with the elapse of time. The narrow peaks become steeper and reach higher heights in relation to the valleys for the longer exposure attained (24 hours). Thus, no change in the general trend towards roughening of the coating surface is observed for $\mathrm{NaF}$ by changing its concentration, though the major roughening noticeable already after 1 hour immersion, continues developing further with time when the more diluted electrolyte is used, and there is no evidence that the situation might have already attained a limiting situation after 1 day. Secondly, neither a change in the trend towards roughening is observed in the case of $\mathrm{NaCl}$ when a more diluted solution is employed. After taking in consideration the different scales employed for the $Z$ axis in Figures 1 and 2, the system is observed to develop roughening with the elapse of time, and rounded features are predominantly formed on the surface. Both concentrations, 0.05 and $0.5 \mathrm{M}$, are sufficiently high for the specific effect of chloride to take place [7], and no major differences are thus observed as it could be expected. Conversely, a dramatic change in the time evolution of roughening is now observed for the $0.05 \mathrm{M} \mathrm{CsCl}$ solution. Namely, roughening is observed to closely match the typical trend of $\mathrm{NaCl}$ solutions, both increasing with the elapse of time and giving rise to more rounded topographic features. Thus, in the less concentrated solution, no cation effect seems to occur at all. 
The SECM observations can be justified if the extent of lixiviation from the coating in each electrolyte is considered. Indeed, gravimetric measurements were done after the coated samples were exposed in the solutions for 1 week, and the results are plotted in Figure 3. The different behaviour of the coated metal in each electrolyte, and the effect of the concentration, could thus be observed. Whereas the mass measured in $\mathrm{NaCl}$ solutions is practically constant for 0.05 and $0.5 \mathrm{M}$, and this value departs only slightly from the reference condition established in distilled water, major changes occur in the other two electrolytes, and they are strongly dependent on the concentration. The greatest lixiviation is observed in $0.05 \mathrm{M} \mathrm{NaF}$, whereas it is rather small compared to $\mathrm{NaCl}$ when the concentration is $0.5 \mathrm{M}$. Conversely, the solution with the lowest loss of mass is $0.05 \mathrm{M} \mathrm{CsCl}$, which is even less than half the lixiviation occurring in distilled water. But higher electrolyte composition leads to very high lixiviation rates, only slightly smaller than those observed in $0.05 \mathrm{M} \mathrm{NaF}$.

Therefore, lixiviation has to be considered in addition to water uptake and the ingress of dissolved ions from the electrolyte as a major contribution to topographic changes in the coating. Indeed, surface roughening was also observed when the SECM experiments were performed in bidistilled water with the only addition of $0.5 \mathrm{mM}$ ferrocene-methanol as redox mediator for imaging. Contrary to the expectation of flat surfaces when imaged by SECM, the maps shown in Figure 4 show major roughening, and the occurrence of a few steep peaks. Such roughening cannot occur as result of blistering in this chloride-free solution, but arises from the lixiviation of components contained in the polymeric film applied on the metal. Furthermore, lixiviation occurs in all the considered electrolytes, thus interfering with the investigation of water uptake and ion transport from the electrolyte, which cannot be studied by SECM in the case of plasticized PVC on nickel. The expected behaviour resulting from water uptake and the specific chloride effect is thus only observable in $0.05 \mathrm{M} \mathrm{CsCl}$ solution, whereas in both $\mathrm{NaCl}$ solutions can be poorly seen due to the greater interference of lixiviation. Conversely, the interference of lixiviation completely hides that effect in the more concentrated $\mathrm{CsCl}$ solution $(0.5 \mathrm{M})$, leading to the apparent observation described above that the roughening decreases with the elapse of time, when this fact basically corresponds to a reduction in the rate of lixiviation with time. Finally, the current results do not allow to distinguish whether a specific effect towards blistering is also produced by fluoride ions, due to the big lixiviation effects occurring in this electrolyte. At this stage, based on the similarity of the maps determined in NaF solutions of varying concentration, and their comparison with those measured in distilled water, lead us to suggest that the fluoride ions, more strongly solvated than chloride ions, may not produce the reported specific effect towards early blistering in coated metals. 
An additional consideration must be made in relation to the occurrence of lixiviation from the polymeric film towards the electrolyte phase. That is, chemical species are released into the electrolyte where the SECM tip is rastered in close proximity to the surface under investigation, and they may affect the electrochemical response of the active electrode. This is an important observation towards the correct operation of SECM, since no changes in the active surface should occur during the measurements. In our work we have taken the caution of measuring the cyclic voltammogram for the oxidation of ferrocene-methanol in the bulk of the electrolyte (i.e., sufficiently far from the imaged surface to avoid interferences from the topography and the local chemical activity of the material) both before and after a SECM map was registered. In this way, possible effects on the stability and reproducibility of the tip surface could be directly observed, and eventually cleaning procedures to be applied if necessary. From the observation of the cyclic voltammograms depicted in Figure 5, which were obtained during the imaging of a plasticized PVC coated nickel specimen immersed in $0.05 \mathrm{M} \mathrm{NaCl}+0.5 \mathrm{mM}$ ferrocene-methanol solution, only a minor and almost negligible blocking effect was observed, which could be accounted for by using normalized currents to draw the SECM maps. Though this effect was found to be almost negligible in this case, major tip surface modification has been observed in some other systems hindering the in situ operation of the technique [18], and must be always checked for.

\section{4.- Conclusions}

Scanning electrochemical microscopy operated in the negative feedback mode allows the water uptake and eventual specific transport effects of solution ions through the polymer coating applied on a metal to be investigated if lixiviation does not play a major role in the system. It has been shown that in the event of lixiviation, changes of the coating topography may occur which compete with those due to water uptake and ion transport from the solution, thus producing interference to their study. Furthermore, the lixiviated species may either block the active surface of the rastering tip or react at the tip surface, and quantitative operation of the SECM is then compromised. The reproducibility and stability of the tip must be checked regularly during the experiments by recording the cyclic voltammograms of the redox mediator in the bulk electrolyte at regular times.

\section{Acknowledgements:}

The authors are grateful to the Ministerio de Ciencia e Innovación (Madrid, Spain) and the European Regional Development Fund (Brussels, Belgium), within the framework 
of Project CTQ2009-14322, under which the present work was carried out. R.G.D. is grateful to Fundação Calouste Gulbenkian (Lisbon, Portugal) for the award of a grant to conduct a research stay at the University of La Laguna.

\section{References:}

1. L.L. Shreir, R.A. Jarman, G.T. Burstein (Eds.), Corrosion, vol. 2, third ed.; Buttherworth-Heinemann, Oxford, 1994, Chapter 14.

2. J.H.W. de Wit, in: P. Marcus, J. Oudar (Eds.), Corrosion Mechanisms in Theory and Practice; Marcel Dekker, New York, 1995, p. 581.

3. G. Grundmeier, A. Simões, in: A.J. Bard, M. Stratmann (Eds.), Encyclopedia of Electrochemistry, vol. 4; Wiley-VCH, Weinheim, 2003, p. 499.

4. A. Forsgren, Corrosion Control Through Organic Coatings; CRC Press, Boca Raton, 2006.

5. J.E.O. Mayne, in: L.L. Shreir, R.A. Jarman, G.T. Burstein (Eds.), Corrosion, vol. 2, third ed.; Butterworths-Heinemann, Oxford, 1994, p. 14:22.

6. R.M. Souto, Y. González-García, S. González, G.T. Burstein, Corros. Sci. 46 (2004) 2621-2628.

7. R.M. Souto, Y. González-García, S. González, Corros. Sci. 50 (2008) 1637-1643.

8. R.M. Souto, Y. González-García, S. González, G.T. Burstein, Electroanalysis 21 (2009) 2569-2574.

9. R.M. Souto, Y. González-García, J. Izquierdo, S. González, Corros. Sci. 52 (2010) 748-753.

10. Y. González-García, J.J. Santana, J. González-Guzmán, J. Izquierdo, S. González, R.M. Souto, Prog. Org. Coat. 69 (2010) 110-117.

11. R.M. Souto, L. Fernández-Mérida, S. González, D.J. Scantlebury, Corros. Sci. 48 (2006) 1182-1192.

12. Y. González-García, S. González, R.M. Souto, Corros. Sci. 49 (2007) 3514-3526.

13. A.J. Bard, F.-R. Fan, M. Mirkin, in: I. Rubinstein (Ed.), Physical Electrochemistry: Principles, Methods, and Applications; Marcel Dekker, New York, 1995, p. 209.

14. A.J. Bard, M.V. Mirkin (Eds.), Scanning Electrochemical Microscopy. Marcel Dekker, New York, 2001.

15. R.M. Souto, Y. González-García, S. González, Prog. Org. Coat. 65 (2009) 435-439.

16. R.G. Duarte, A.S. Castela, M.G.S. Ferreira, Prog. Org. Coat. 57 (2006) 408-415.

17. R.G. Duarte, A.S. Castela, M.G.S. Ferreira, Prog. Org. Coat. 65 (2009) 197-205.

18. J. Izquierdo, J.J. Santana, S. González, R.M. Souto, Electrochim. Acta 55 (2010) 8791-8800. 

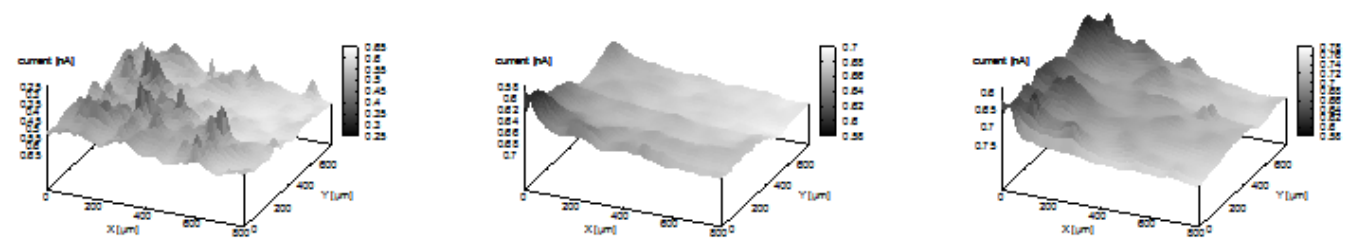

(a)
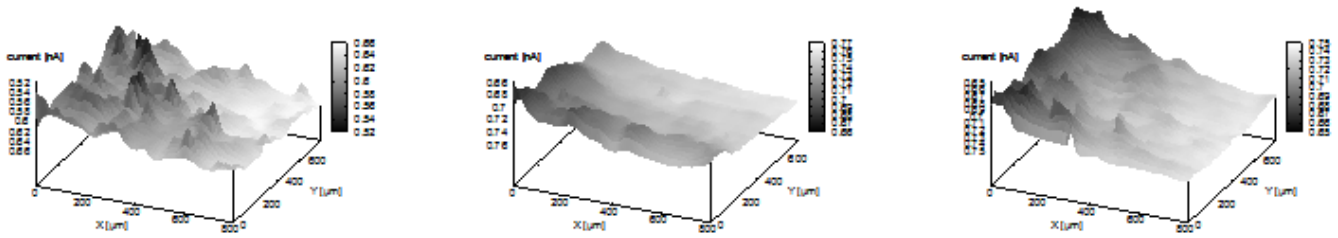

(b)
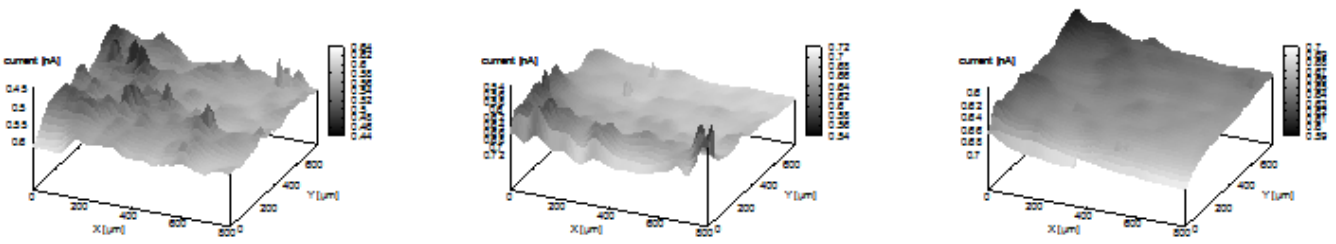

(c)

Figure 1: SECM measurements on PVC plastisol coated nickel foils. Tip-substrate distance: $15 \mu \mathrm{m}$. Tip potential: $+0.50 \mathrm{~V}$ vs. $\mathrm{Ag} / \mathrm{AgCl} / \mathrm{KCl}$ (saturated) reference electrode. Values of $Z$ axis: current, nA. The figures represent an area of $800 \mu \mathrm{m} \times 800$ $\mu \mathrm{m}$ in $X$ and $Y$ directions. From top to bottom: (a) 1, (b) 6, and (c) $24 \mathrm{~h}$ immersion in the corresponding test solution $+0.5 \mathrm{mM}$ ferrocene-methanol. Concentration of the test solution: $0.5 \mathrm{M}$.

0.5 M NaF
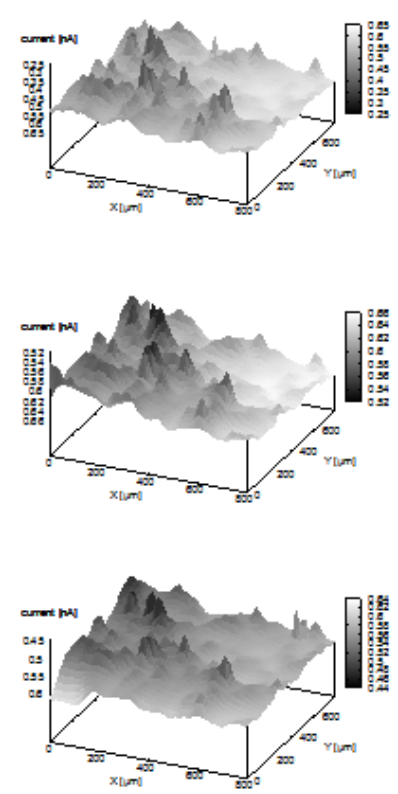

$0.5 \mathrm{M} \mathrm{NaCl}$
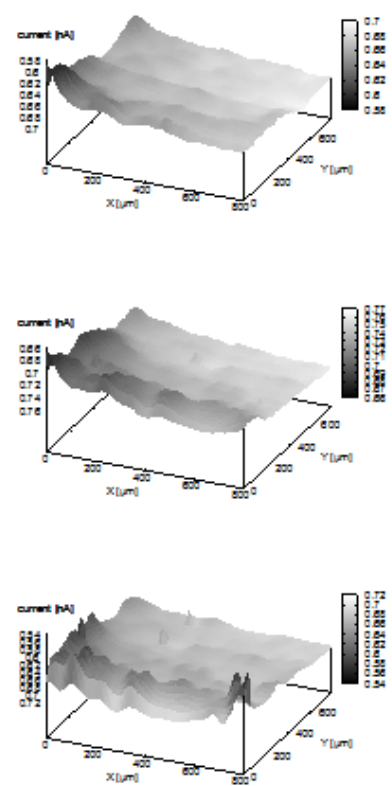

0.5 M CsCl

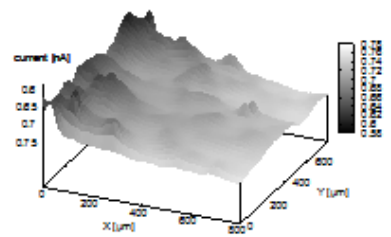

(a)

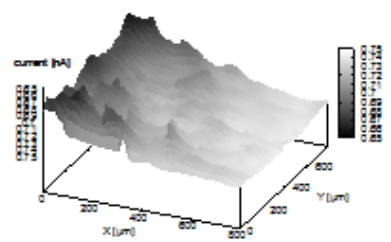

(b)

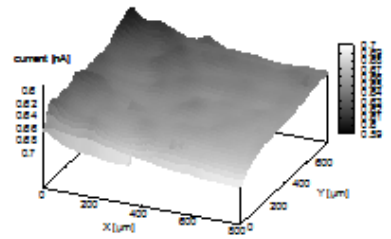

Figure 2: SECM measurements on PVC plastisol coated nickel foils. Tip-substrate distance: $15 \mu \mathrm{m}$. Tip potential: $+0.50 \mathrm{~V}$ vs. $\mathrm{Ag} / \mathrm{AgCl} / \mathrm{KCl}$ (saturated) reference electrode. Values of $Z$ axis: current, $\mathrm{nA}$. The figures represent an area of $800 \mu \mathrm{m} \times 800$ $\mu \mathrm{m}$ in $X$ and $Y$ directions. From top to bottom: (a) 1, (b) 6, and (c) $24 \mathrm{~h}$ immersion in the corresponding test solution $+0.5 \mathrm{mM}$ ferrocene-methanol. Concentration of the test solution: $0.05 \mathrm{M}$. 


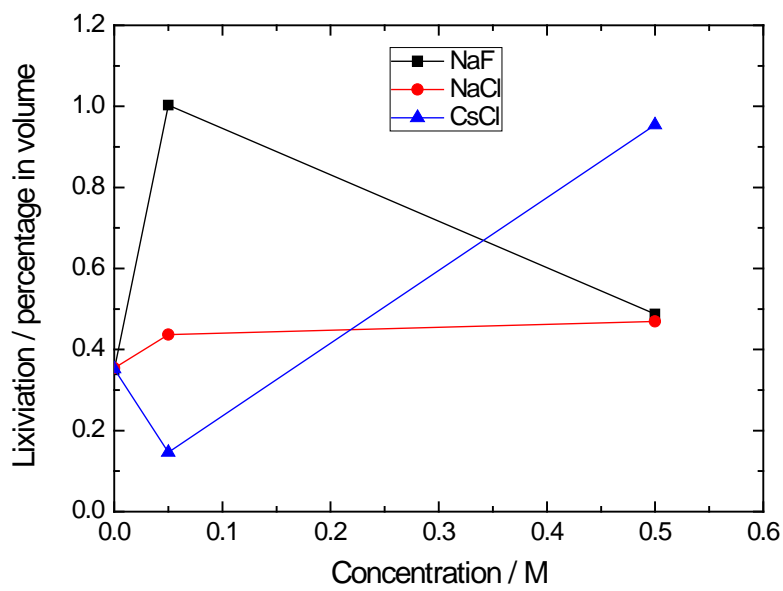

Figure 3: Gravimetric changes related to lixiviation of chemical components from the polymeric coating applied on nickel foils during immersion in $\mathrm{NaF}, \mathrm{NaCl}$ and $\mathrm{CsCl}$ aqueous solutions of varying concentration. The measurements were performed after 1 week exposure to the test environments.

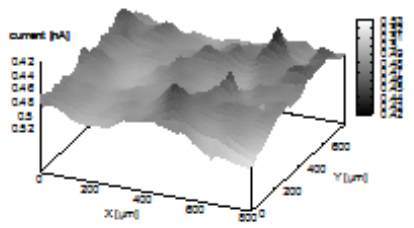

(a)

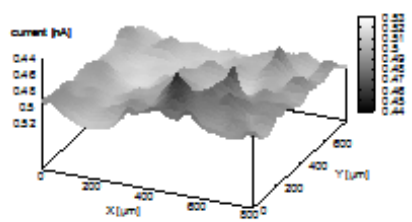

(b)

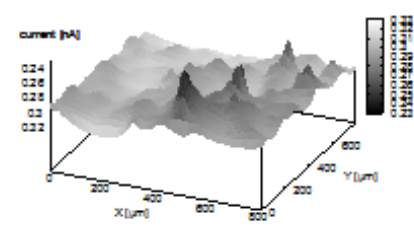

(c)

Figure 4: SECM measurements on PVC plastisol coated nickel foils. Tip-substrate distance: $15 \mu \mathrm{m}$. Tip potential: $+0.50 \mathrm{~V}$ vs. $\mathrm{Ag} / \mathrm{AgCl} / \mathrm{KCl}$ (saturated) reference electrode. Values of $Z$ axis: current, nA. The figures represent an area of $800 \mu \mathrm{m} \times 800$ $\mu \mathrm{m}$ in $X$ and $Y$ directions. From top to bottom: (a) 1, (b) 6, and (c) $24 \mathrm{~h}$ immersion in the bidistilled water containing only $0.5 \mathrm{mM}$ ferrocene-methanol.

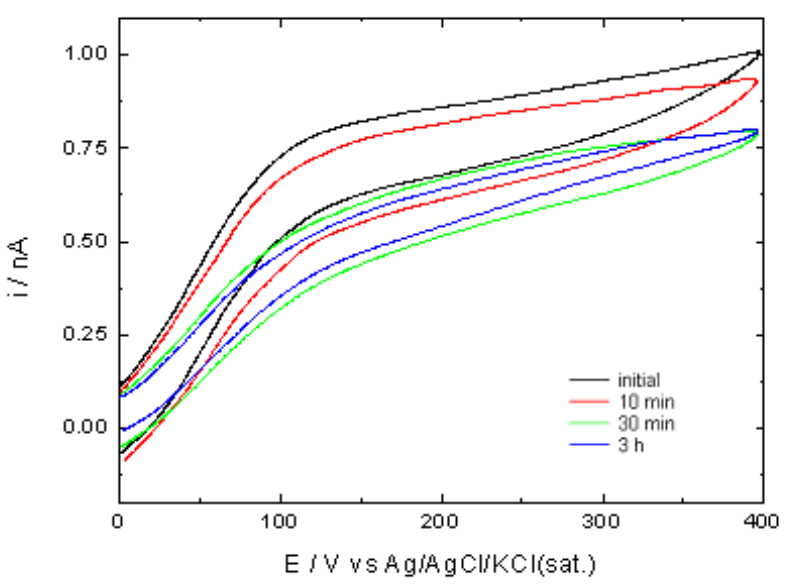

Figure 5: Voltammetric profiles of the platinum microelectrode in $0.05 \mathrm{M} \mathrm{NaCl}+0.5$ $\mathrm{mM}$ ferrocene-methanol recorded in the proximity of the PVC plastisol coated nickel foil. Tip-substrate distance: $15 \mu \mathrm{m}$. Immersion times are given in the figure. $v=0.01 \mathrm{~V}$ $\mathrm{s}^{-1}$. 